\title{
Detection of Human Bocavirus in Children Suffering from Respiratory Tract Infection in Diyala Province Zaid Taha Yaseen(FICMS) ${ }^{1}$, Mohammed Kh Khudair $\left.\mathrm{PhD}\right)^{2}$, Asmaa $\mathbf{S}$ Naseef(BSc $)^{3}$, Jalil I Alezzi $(\mathrm{PhD})^{4}$
} Abstract

Background: Human Boca virus (HBoV) is one of the viral infections present worldwide. Objective: To determine the role of $\mathrm{HBoV}$ in respiratory tract infection.

Patients and Methods: Cross sectional study consists of 160 (Pharyngeal secretions and blood ) samples were collected from children who attended Al-Zahraa Hospital for respiratory complaints during the period from October 1st 2018 to April 30th 2019, including both genders and ages ranging from ( 3 months to 10 years). The samples were divided into two groups. First group consisting of (80) blood samples for patients, while the second group (80) sample swabs from the pharynx.

Results: The prevalence of $\mathrm{HBoV}$ using PCR technique was 38.3\%. Those less than 2 years showed the highest rate of infection $43.5 \%$, followed by $5-7$ years $42.9 \%$ and $2-4$ years $33.3 \%$ while the lowest percentage in the age group (8-10 years) $28.5 \%$. A high rate of $\operatorname{IgG}$ was recorded in age group less than 2 years old $51.3 \%$, followed by the category of 5-7 and 2-4 years with $28.6 \%$ and $22.2 \%$ respectively.

Conclusion: A high rate of $\mathrm{HBoV}$ infection in children with respiratory illness in Diyala province.

Keywords: Human Bocavirus, respiratory tract infections, PCR, ELISA.

Corresponding Author: zaidalzubaidi39@gmail.com

Received: $18^{\text {th }}$ December 2019

Accepted: $26^{\text {th }}$ April 2020

DOI:https://doi.org/10.26505/DJM.18025091218

\footnotetext{
${ }^{1}$ Diyala Health Directorate-Al Zahraa Hospital -Diyala-Iraq

2,3 College of Sciences- University of Diyala-Diyala-Iraq

${ }^{4}$ College of Medicine-University of Diyala- Diyala-Iraq
}

\section{Introduction}

Pathogenic viruses are a prominent causes of lower respiratory infection, [1,2].Human bocavirus $(\mathrm{HBoV})$ is one of the viral infections present worldwide. It was first identified in 2005 by examining the nasal pharyngeal secretions of children with

respiratory infections. It belongs to the family Parvoviridae and subfamily Parvovirinae. Human bocaviruses are single strand DNA viruses. Four serotypes of HBoVs have been described [2,3] Three species $\mathrm{HBoV} 2, \mathrm{HBoV} 3$, and $\mathrm{HBoV} 4$ were 
found mainly in stool samples which cause gastroenteritis [3-7]. While Human bocavirus 1 causes upper and lower respiratory tract infection(RTI). Infection with this type of virus is common all over the world and infection occurs throughout the year but prevalent during winter and spring. Epidemiological revisions indicated that the HBoV1 virus is worldwide spread and other serotypes 3-4 viruses are also common in children with respiratory system infections [5-10]. The prevalence HBoV1 DNA in young children with RTI is about $10 \%$ but in some researches showed up to $33 \%$ $[1,11.12]$. The most common clinical diagnoses associated with HBoV1 RTI are upper respiratory tract infections, bronchiolitis, pneumonia, bronchitis, asthma exacerbation and pharyngitis [7-13]. Human bocavirus 1 is identified by several methods, including serological methods like western blotting, immunofluorescence assays [8,1417], as well as enzyme immunoassay (EIA) and enzyme linked immunosorbent assay to detect $\operatorname{IgG}$ and $\operatorname{IgM}$ antibodies [9,18-23]. Atyah in 2017 in Iraq showed $\mathrm{HBoV}$ infection was 48/195 $24.62 \%$ using Real Time PCR technique [12].Molecular methods used to detect HBoV1 virus using Polymerase Chain Reaction (PCR) technique are the most accurate and modern $[9,15,24]$ .The objective of this study is to define the role of $\mathrm{HBoV}$ in respiratory tract infection using PCR methods and ELISA.

\section{Patients and Methods}

Sample size and design: study was done in Al Zahraa hospital / Diyala province for the period from October 1st 2018 to April 30th 2019. One -hundred sixty samples collected by the authors from children. These samples were divided into 80 blood samples and 80 pharyngeal swabs. The blood samples consist of 35 females and 45 males. The swabs samples consist of 35 females and 45 males, Samples were collected from hospitalized children, outpatient clinic attendees suffering from respiratory infections who were aged from 3 months to 10 years. A three $\mathrm{ml}$ of venous blood withdrawn by using plastic medical syringes. Blood has been expended in test tubes and left for 30 minutes at room temperature to coagulate. The serum was separated by a centrifuge for 5 minutes $(3000$ cycles / min) and stored at $-20^{\circ} \mathrm{C}$ until use for $\mathrm{HBoV} \operatorname{IgG}$ and $\operatorname{IgM}$ antibodies finding. The swabs were collected by taking a swab from the pharynx and a normal saline solution was added for sterilization and stored at $-70^{\circ} \mathrm{C}$ until usage for PCR. Serological Procedure: Human Bocavirus IgG and IgM antibodies levels were detected by double antigen sandwich enzyme -linked immunosorbent assay. The ELISA Kits provided by GenAsia Biotech (Cat.no. GAE5461HM) in all patient's serum samples agreeing to the manufacturer's directions.

Qualitative

polymerase

chain

reaction:Viral nucleic acid was extracted from $100 \mu \mathrm{l}$ of the samples using RIBO PreP nucleic acid withdrawal Kit Cat. No. GA-E5460HM Amplisens biotechnologies ,Russia agreeing to the manufacturer's guidelines. The existence of $\mathrm{HBoV}$ genomes were identified from the removed nucleic 
acid by qualitative polymerase chain reaction (PCR) with exact primers the NP-1 primers BoV18 and BoV542R [6,9] Table(3). Polymerase chain reaction combination was organized with $20 \mu \mathrm{l}$ of lyophilized Master Mix (Korea /Bioneer), 13 $\mu$ l of nuclease unrestricted water, $1 \mu \mathrm{l}$ of each primer at 10 $\mathrm{pmol} / \mu \mathrm{l}$, and $5 \mu \mathrm{l}$ of DNA template, $\mathrm{MgCl}_{2}$, $\mathrm{KCl}$,dNNTPs, Tris-HCl PH 9.0 ,Tag DNAPolymerase, Stabilizer tracing dye PCR Thermocycling circumstances of $95^{\circ} \mathrm{C}$ (initial denaturation) for $10 \mathrm{~min}$, monitored by 50 cycles of denaturation at $94^{\circ} \mathrm{C}$ for $30 \mathrm{sec}$. and toughening at $53 \mathrm{C}^{\circ}$ for $40 \mathrm{sec}$, then the final delay step at $72^{\circ} \mathrm{C}$ for 1 min settled the reaction program.

Ethical consent:The study protocol and the questionnaires were directed agreeing to the principles of the Declaration of Helsinki, as well as revised and agreed by the Ethical Research Committee of College of medicine, University of Diyala. Verbal consents were taken from the parents and caregivers of children enrolled in the study.

\section{Statistical analysis}

The data were processed and analyzed using the Statistical Package for Social Sciences version 20 (SPSS Inc., Chicago, IL, USA. The results were expressed using percentage and frequencies. A p-value $<0.05$ was considered significant.

\section{Results}

Prevalence of HBoV- IgG for study samples: The results of our work elucidated seropositivity $\mathrm{IgG}$ antibody test for infected patients with $\mathrm{HBoV}$ for 28 samples comprised 35\%.

Present study group for IgG HBoV antibodies according to age groups: The results of the present study showed that the age group less than 2 years documented the highest percentage for IgG $51.3 \%$, while the lowermost percentage was in the age group 2-4 years $22.2 \%$. The age group 5-7 years recorded the percentage $28.6 \%$. No IgG was reported for 8-10 year's age group, with an important variance when matched with control group $(\mathrm{P}<0.05)$ Table $(1)$.

Table (1) : The positive \& negative carrier for IgG $\mathrm{HBoV}$ antibodies according to age groups

\begin{tabular}{|l|c||c||c|c||c||c||}
\hline \multicolumn{2}{|c|}{ Groups } & \multicolumn{2}{c|}{ Negative } & \multicolumn{2}{l|}{ Total } \\
\hline \hline & No & $\mathbf{\%}$ & No & \% & No & \% \\
\hline \hline Less than 2 years & 20 & 51.3 & 19 & 48.7 & 39 & 48.8 \\
\hline \hline 2-4 Year & 6 & 22.2 & 21 & 77.8 & 27 & 33.8 \\
\hline 5-7 Year & 2 & 28.6 & 5 & 71.4 & 7 & 8.8 \\
\hline \hline 8-10 Year & 0 & 0.0 & 7 & 100 & 7 & 8.8 \\
\hline \hline Total & 28 & 35.0 & 52 & 65.0 & 80 & 100 \\
\hline * V Value $=0.016$
\end{tabular}

The present study group for $\mathrm{HBoV}$ IgG antibodies according genders. The results of this study showed insignificant variance in
$\mathrm{HBoV}$ infection in both genders. The proportion of infection was $37.8 \%$ for boys and $31.4 \%$ for girls as in Table(2). 
Table(2): The positive and negative carrier for IgG HBoV antibodies for both genders

\begin{tabular}{|c|c|c|c|c|c|c|c|}
\hline & Positi & & $\overline{\text { egat }}$ & & Total & & \multirow{3}{*}{ P Value } \\
\hline Genders & No & $\%$ & No & $\%$ & No & $\%$ & \\
\hline Female & 11 & 31.4 & 24 & 68.6 & 35 & 43.8 & \\
\hline Male & 17 & 37.8 & 28 & 62.2 & 45 & 56.3 & \multirow[t]{2}{*}{$\mathrm{P}=0.55$} \\
\hline Total & 28 & 35.0 & 52 & 65.0 & 80 & 100 & \\
\hline
\end{tabular}

The occurrence of HBoV- IgM antibodies for study samples The results of the present test for infected patients with $\mathrm{HBoV}$ at 7 study revealed seropositivity $\operatorname{IgM}$ antibody samples and $8.8 \%$.

Table(3): Shows the primers used for HBoV DNA amplification

\begin{tabular}{||l||l||c||}
\hline \multicolumn{1}{|c||}{ Primers } & \multicolumn{1}{c|}{ Sequence(5'-3') } & Size (bp) \\
\hline HBoV188F & GAGCTCTGTAAGTACTATTAC & 354 \\
\hline HBoV542R & CTCTGTGTTGACTGAATACAG & 354 \\
\hline
\end{tabular}

Molecular Diagnosis of $\mathrm{HBoV}$ for Infected

Children:This study disclosed that among 80 samples gained from children with (RTI), there were 31 positive results for $\mathrm{HBoV}$
DNA (38.8\%) and $49(61.2 \%)$ samples were negative by qualitative PCR. This designates high infection rate.

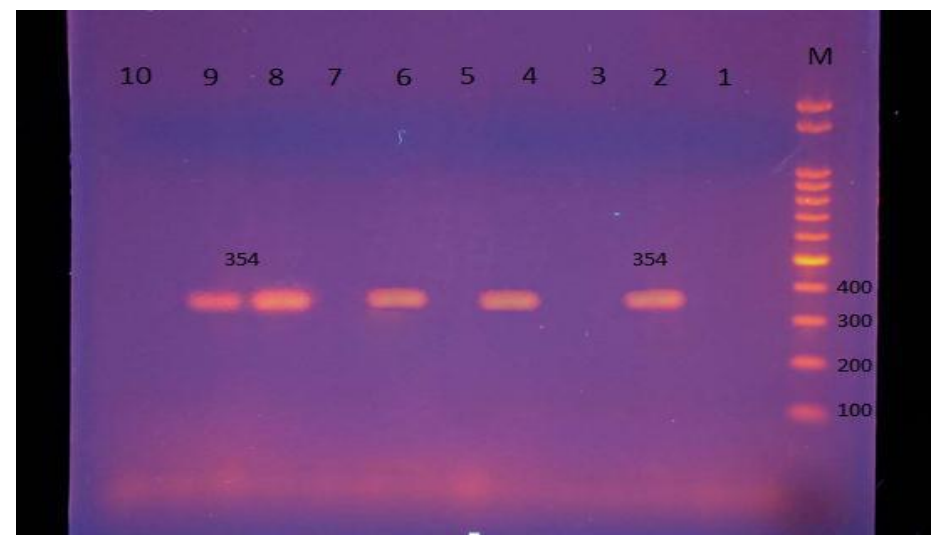

Figure (1): Gel electrophoresis for PCR produce to detect Human bocavirus, $354 \mathrm{bp}$, via (1.5\%) agarose for 45 minutes at 75 volt. $\mathrm{M}$ - 100 bp ladder. $(2,4,6,8,9)$.PCR produce of positive isolates from samples, negative $(1,3,5,7,10)$

Demographic characteristics of children While age group 2-4 years who were 27 with (RTI) and their association to HBoV: samples, 9 of them were positive $33.3 \%$. Variation of $\mathrm{HBoV}$ infection between While the age group 5-7 years was 7 different age groups.The results of the samples, 3 were positive $42.9 \%$. Lastly, the current study demonstrated that the age group age group 8-10 years 7, two of them were less than two years who were 39 cases, 17 of positive $28.5 \%$, with insignificant variance them were positive with percentage $43.5 \%$. $\quad(\mathrm{P}>0.05)$ as shown in Table (4). 
Table (4): Positive and negative cases according to age groups

\begin{tabular}{|l|c|c||c|c||c|c||c||}
\hline \multicolumn{3}{|c||}{ Positive } & \multicolumn{2}{c||}{ Negative } & \multicolumn{3}{c|}{ Total } \\
\hline Age Groups & No & $\%$ & No & $\%$ & No & $\%$ & \\
\hline \hline Less than two years & 17 & 43.5 & 23 & 59.0 & 39 & 48.8 & \\
\hline \hline 2-4 Year & 9 & 33.3 & 19 & 70.4 & 27 & 33.8 & P $=0.55$ \\
\hline \hline 5-7 Year & 3 & 42.9 & 4 & 57.1 & 7 & 8.8 & \\
\hline \hline 8-10 Year & 2 & 28.5 & 3 & 42.9 & 7 & 8.8 & \\
\hline \hline Total & 31 & 38.8 & 49 & 61.3 & 80 & 100 & \\
\hline
\end{tabular}

Relationship between $\mathrm{HBoV}$ infection and gender: The outcomes of the current study showed insignificant variances in $\mathrm{HBoV}$ infection in both genders. The proportion of infection among boys was (40.0\%) matched with $(37.1 \%)$ for female as shown in Table (5). Our study showed that the incidence of infection between males and females is Congregated.

Table (5): The positive and negative samples for genders

\begin{tabular}{||l|c|c|c|c||c|c||c||}
\hline \multicolumn{3}{|c||}{ Positive } & \multicolumn{2}{c||}{ Negative } & Total & \multicolumn{2}{c||}{ P Value } \\
\hline Genders & No & $\%$ & No & $\%$ & No & $\%$ & \\
\hline \hline Female & 13 & 37.1 & 22 & 62.9 & 35 & 43.8 & \multirow{2}{*}{$\mathrm{P}=0.79$} \\
\hline \hline Male & 18 & 40.0 & 27 & 60.0 & 45 & 56.3 & \\
\hline \hline Total & 31 & 38.8 & 49 & 61.3 & 80 & 100 & \\
\hline
\end{tabular}

\section{Discussion}

The occurrence of $\mathrm{HBoV}$ differs among different nations of the world due to climatic and topographical influences as well as health care or cultural and socioeconomic level. Numerous studies have designated that $\mathrm{HBoV}$ occurrence is higher in winter $[10,11]$.The results of this study displayed that the proportion of infection was $38.8 \%$ by qualitative PCR. In earlier study done by Atyah in 2017 in Iraq showed HBoV infection was 48/195 $24.62 \%$ using Real Time PCR technique [12]. A study done in Egypt to identify the DNA of the virus in nasopharyngeal swab in 2016 revealed that the infection proportion was $56.8 \%$ for 95 samples [13]. A study achieved in China in 2012 using Real Time PCR showed the occurrence rate was $24.6 \%$ [14].This variance can be elucidated by several factors including sampling procedures, study groups, climate disparities and the sensitivity of several tests to identify the virus [15]. The outcomes of our study revealed that the age group less than two years verified the highest rate $43.5 \%$ in PCR results, followed by $42.9 \%$ in age group 5-7 years, and $33.3 \%$ in age group 2-4 years). While the lowermost 
proportion was $28.5 \%$ in age group (8-10) years. A study achieved by Atyah in 2017 in Iraq showed that the frequency of the virus in the age group 1-2 years was $68.75 \%$ followed by the age group 2-5 years $29.17 \%$ and the age group 5-15 years 2.08\% [12]. Another study observed a high incidence of $\mathrm{HBoV}$ in children aged less than1 year) $57.9 \%[16]$. Another study showed the rate of infection in the age group less than two years $63.91 \%$ [17].Primary infection with $\mathrm{HBoV}$ occurs early in children age less than 2 years) [18] .Newborns are less likely to have the infection because of protective antibodies obtained from mother [19].The results of the this study relative to gender showed that the proportion of infection in males $40.0 \%$, while the rate of infection in females $37.1 \%$ and infection between males and females was congregated. Our results differ from study performed in Egypt where the infection in males consisted $78.86 \%$, and in the females $21.14 \%$ [16]. A study performed in China in 2016 appeared infections in males $65.9 \%$ while in female was $34.1 \%$ [17] which showed no statistical differences. Concerning IgG seropositivity result was $35 \%$ with an important variance when matched with control group. Our results agreed to that performed in China by Lin et al which was $31 \%$ of children with lower respiratory tract infections. All age groups of patients showed an upper level of antibodies to $\mathrm{HBoV}$ IgG using the ELISA technique and using human bocavirus VP2 virus-like elements [20]. Our study is inconsistent with that conducted in Finland where $\operatorname{IgG}$ antibody detected in
111/258 43\% [21]. The results of the present study revealed that the age group less than two years recorded the highest rate for $\mathrm{IgG}$ $51.3 \%$, while the lowest rate was in the age group 2-4 years $22.2 \%$. The age group 5-7 years documented $28.6 \%$. No IgG was reported in the 8-10 year's age group. Seroepidemiological study in Jamaica in 2012 specified that more than $80 \%$ of children are liable to $\mathrm{HBoV}$ at the age of two years [22].Another study in Italy in 2012 specified that the occurrence of $\operatorname{IgG}$ was $73.7 \%$ in children aged one day to 5 months and $51.4 \%$ in the 6-11 month age group, $64.2 \%$ in the 2 4 years and the high proportion of immunoglobulin $\mathrm{IgG}$ in the age group 5-9 years $96.4 \%$ [23]. Our results showed the seropositive for IgG antibody amongst males $37.8 \%$ while the rate of $\mathrm{IgG}$ in females $31.4 \%$. This is in agreement with a study performed in Jamaica [22]. The results of this study revealed seropositivity IgM antibody for infected children with $\mathrm{HBoV} 8.8 \%$, these results were slightly less than that reported in Egypt in 2017 where, the occurrence of IgM 16 / $12313 \%$ by ELISA [16]. As well as in Finland and Germany $[24,25]$. This differences may be due to social and environmental conditions, as well as the type of kit used for diagnosis and sample preparation from the infected patients.

\section{Conclusions}

The study showed a high rate of $\mathrm{HBoV}$ infection in children with respiratory infections in Diyala province, the age groups less than 2 years had the highest incidence of 
infection and the lowest incidence was in the 8-10 years age group using the PCR method.

\section{Recommendations}

The clinician should be aware about human bocavirus in children with respiratory tract infection at least in our locality.

\section{References}

[1]Andrew T. Pavia ;Viral infections of the lower respiratory tract: old viruses, new viruses, and the role of diagnosis. Clinical Infectious Diseases, 2011, (52). suppl_4: S284-S289.

[2]Allander T, Tammi MT, Eriksson M, Bjerkner A, Tiveljung-Lindell A, Andersson B.; Cloning of a human parvovirus by molecular screening of respiratory tract samples. Proceed. of the Nat. Aca. of Sci. 2005, 102.(36): 12891-12896.

[3]Paloniemi M , Lappalainen S, Salminen M, Kätkä M, Kantola K, Hedman L, et al. Human bocaviruses are commonly found in stools of hospitalized children without causal association to acute gastroenteritis. European journal of pediatrics, 2014, 173.8: 10511057.

[4]M. M. Alam, A. Khurfhid ,Sh. Shaukat.,S. Sharif ,R. Muhammad S. M. Angez et al. 'Human bocavirus in Pakistani children with gastroenteritis'. Journal of medical virology, 2015, 87.4: 656663.

[5]T. Jartti K. Hedman L.Jartti O. Ruuskanen T. Allander M. SöderlundVenermo: Human bocavirus - the first 5 years. Reviews in medical virology, 2012, 22.1: 46-64.
[6]Yu Deng, Xiaoyang Gu, Xiaodong Zhao Jian Luo, Zhengxiu Luo, Lijia Wang. High Viral Load of Human Bocavirus Correlates with Duration of Wheezing in Children with Severe Lower Respiratory Tract Infection; PLoS One. 2012; 7(3): e34353, doi: 10.1371/journal.pone.0034353 [7]O. Schildgen,A. Müller, T. Allander Ian M. Mackay, S. Völz, B. Kupferet al :Human bocavirus: passenger or pathogen in acute respiratory tract infections?. Clinical microbiology reviews, 2008, 21.2: 291-304. [8]Jin Y, Cheng Wx, Xu Zq, Liu N, Yu $\mathrm{Jm}, \mathrm{Li} \mathrm{Hy}$,et al. : High prevalence of human bocavirus 2 and its role in childhood acute gastroenteritis in China. Journal of Clinical Virology, 2011, 52.3: 251-253.

[9]K. Kantola, L. Hedman, J. Arthur, A. Alibeto, E. Delwart, T. Jartti, et al. Seroepidemiology of human bocaviruses 14. Journal of Infectious Diseases, 2011, 204.9: 1403-1412.

[10]Chow, Brian DW; HUANG, Yung T.; ESPER, Frank P. Evidence of human bocavirus circulating in children and adults, Cleveland, Ohio. Journal of Clinical Virology, 2008, 43.3: 302-306.

[11]N. Bastien, N. Chui, J. L Robinson, B. E Lee, K. Dust, L. Hart, et al. Detection of human bocavirus in Canadian children in a 1year study. Journal of clinical microbiology, 2007, 45.2: 610-613.

[12]Noor S. Atyah, Hula Y. Fadhil, Iman M. Aufi, Faisal G. Al-Hamadani: First identification of Human Bocavirus (HBoV) in Iraqi children with respiratory 
complications. Journal of Pharmacy and Biological Sciences, 2017; 12(6): 15-20. [13]A.S Abdel-Moneim, M. M Kamel, Dina $H$ Hamed 'Safaa S Hassan, May S Soliman, S. A. Al-Quraishy., et al. A novel primer set for improved direct gene sequencing of human bocavirus genotype-1 from clinical samples. Journal of virological methods, 2016; 228: 108-113.

[14]N. Brieu, G. Guyon, M. Rodière, M. Segondy, V. Foulongne. : Human Bocavirus Infection in Children With Respiratory Tract Disease, Pediatr Infect Dis J , 27 (11), 96973.Nov 2008 ,

DOI: 10.1097/INF.0b013e31817acfaa

[15]Susanna K P Lau, Cyril C Y Yip, TakLun Que, Rodney A Lee, Rex K H AuYeung, Boping Zhou, et al. Clinical and molecular epidemiology of human bocavirus in respiratory and fecal samples from children in Hong Kong. The Journal of infectious diseases, 2007; 196.7: 986-993.

[16]Amr, Ghada E., ATEF, Dina M.; ELBEHEDY Rabab. Detection of Human Bocavirus in Egyptian Children Suffering from Acute Lower Respiratory Tract Infection. Int. J. Curr. Microbiol. App. Sci, 2017; 6.2: 809-816.

[17]Wujun Jiang, Fang Yin, Weifang Zhou, Yongdong Yan, Wei Ji :. Clinical significance of different virus load of human bocavirus in patients with lower respiratory tract infection. Scientific reports, 2016; 6: 20246.

[18]A. S Abdel-Moneim, M. M Kamel, A. S Al-Ghamdi, M. I R Al-Malky. : Detection of bocavirus in children suffering from acute respiratory tract infections in Saudi Arabia. PloS one, 2013; 8.1: e55500. DOI: 10.1371/journal.pone.0055500 [19]M. Meriluoto, L. Hedman, L. Tanner, V. Simell, M. Mäkinen, S. Simell, et al. Association of human bocavirus 1 infection with respiratory disease in childhood followup study, Finland. Emerging infectious diseases, 2012; 18.2: 264.

DOI: 10.3201/eid1802.111293

[20]F. Lin, W. Guan, F. Cheng, . Yang, D. Pintel, J. Qiu:. ELISAs using human bocavirus VP2 virus-like particles for detection of antibodies against $\mathrm{HBoV}$. Journal of virological methods, 2008; 149.1: 110-117.

DOI: 10.1016/j.jviromet.2007.12.016

[21]M. Söderlund-Venermo, A. Lahtinen, T. Jartti, L.Hedman, K. Kemppainen, P. Lehtinen, et al. Clinical assessment and improved diagnosis of bocavirus-induced wheezing in children, Finland. Emerg infectious diseases, 2009, (15).9: 1423. doi: 10.3201/eid1509.090204

[22]J. W. Hustedt,' C. Christie, M. M. Hustedt, D. Esposito, and M. Vazquez. Seroepidemiology of human bocavirus infection in Jamaica. PLoS One, 2012; 7.5: e38206. doi: 10.1371/journal.pone.0038206 [23]M Guido, A Zizza, S Bredl, J Lindner, A De Donno, $M$ Quattrocchi., et al. Seroepidemiology of human bocavirus in Apulia, Italy. Clinical Microbiology and Infection, 2012; 18.4: E74-E76. DOI: 10.1111/j.1469-0691.2011.03756.x [24]M. Xu, B.t Arku, T. Jartti ' J. Koskinen, V. Peltola, K. Hedman, et al. 
Comparative Diagnosis of Human Bocavirus 1 Respiratory Infection With Messenger RNA Reverse-Transcription Polymerase Chain Reaction (PCR), DNA Quantitative PCR, and Serology. The Journal of infectious diseases, 2017; 215.10: 1551-1557. [25]J.Lindner, L.Karalar, S. Zehentmeier, A. Plentz, H. Pfister, W. Struff, et al. Humoral immune response against human bocavirus VP2 virus-like particles. Viral immunology, 2008; 21.4: 443-450. 